\title{
Natural fibers characterization by inverse gas chromatography
}

\author{
N. Cordeiro ${ }^{a, *}$, C. Gouveia ${ }^{a}$, A.G.O. Moraes $^{b}$, S.C. Amico ${ }^{b}$ \\ a Competence Centre in Exact Science and Engineering, University of Madeira, 9000-390 Funchal, Portugal \\ ${ }^{\mathrm{b}}$ Department of Materials Engineering, Federal University of Rio Grande do Sul (UFRGS), PO Box 15010, 91501-970 Porto Alegre-RS, Brazil
}

\section{A R T I C L E I N F O}

\section{Article history:}

Received 7 June 2010

Received in revised form 28 October 2010

Accepted 2 November 2010

Available online 9 November 2010

\section{Keywords:}

Vegetable fibers

Inverse gas chromatography

Surface properties

Alkaline treatment

\section{Introduction}

The intrinsic characteristics of vegetable fibers are attracting much attention nowadays (Amico, Angrizani, \& Drummond, 2010). Their biodegradability can contribute to a healthier ecosystem, and their renewable character, low cost and reasonable performance when used to produce composite materials may find uses in various sectors, especially the automotive industry (Satyanarayana et al., 2005). Due to their natural origin, the properties of vegetable fibers are strongly affected by many factors such as variety, climate, maturity, harvesting, retting degree, decortication and disintegration (mechanical or steam explosion) (Kalia, Kaith, \& Kaur, 2009). Besides, they are easily modified via chemical or physical treatments. A comprehensive characterization of these fibers may not only supply data for different industrial sectors which already use them, but also enable new uses for these abundantly available resources (Satyanarayana, Guimarães, \& Wypych, 2007).

Vegetable fibers can be classified according to the part of the plant from where they are retrieved in leaf (e.g. cantala, curaua, date palm, henequen, pineapple, sisal), bast (e.g. flax, hemp, jute, ramie), fruit (e.g. coir, silk floss, oil palm), seed (e.g. cotton), grass (alfa, bagasse, bamboo) and stalk (straw) fibers (Kalia et al., 2009). Vegetable fibers can be considered as naturally occurring composites, consisting mainly of helically wound cellulose microfibrils bound together by lignin and hemicellulose. Lignin keeps water in

\footnotetext{
* Corresponding author. Tel.: +351 291705 036; fax: +351 291705149.

E-mail addresses: ncordeiro@uma.pt (N. Cordeiro), catarinagouveia@uma.pt (C. Gouveia), alvaro.moraes@ufrgs.br (A.G.O. Moraes), amico@ufrgs.br (S.C. Amico).
}

the fibers, acting as a protection against biological attack and as a stiffener. Hemicellulose molecules are believed to be a compatibilizer between cellulose and lignin and are hydrogen bonded to cellulose, acting as cementing matrix between cellulose microfibrils, yielding a network which represents the main structural block of the fiber cell. The hydrophobic lignin network also affects the properties of the primary network, increasing the overall stiffness of the cellulose/hemicellulose composite (John \& Thomas, 2008).

Cellulose is a natural linear polymer consisting of $D$ anhydroglucose $\left(\mathrm{C}_{6} \mathrm{H}_{11} \mathrm{O}_{5}\right)$ repeating units joined by $1,4-\beta-\mathrm{D}-$ glycosidic linkages at the $C_{1}$ and $C_{4}$ positions. The degree of polymerization (DP) is around 10,000 and each repeating unit contains three hydroxyl $(\mathrm{OH})$ groups. The ability of these groups to make hydrogen bonds plays a major role in the crystalline packing of cellulose and also governs its physical properties. Solid cellulose comprises a microcrystalline structure with higher (crystalline) and lower order (amorphous) regions. The crystal nature (monoclinic sphenodic) of naturally occurring cellulose is known as cellulose I (John \& Thomas, 2008).

Hemicellulose comprises a group of polysaccharides composed of a combination of 5- and 6-carbon ring sugars. Hemicellulose differs from cellulose because the former contains several different sugar units, exhibits a considerable degree of chain branching giving rise to its non-crystalline nature, and its DP is just around 50-300. Hemicellulose is very hydrophilic, partly soluble in water, soluble in alkali and easily hydrolyzed in acids (John \& Thomas, 2008; Spinacé, Lambert, Fermoselli, \& De Paoli, 2009).

Lignin is a complex three-dimensional hydrocarbon copolymer of aliphatic and aromatic constituents with very high molecular weight. Lignin is totally amorphous and hydrophobic in nature, 
showing the lowest water adsorption among the fiber components. Lignin is not hydrolyzed by acids being insoluble in most solvents but soluble in alkali (Spinacé et al., 2009).

The available literature is still poor on the characterization of many vegetable fibers, especially considering their surface characteristics. Inverse Gas Chromatography (IGC) has been used to determine the surface properties of polymers (Cordeiro, Aurenty, Belgacem, Gandini, \& Neto, 1997; Wu, Que, \& Al-Saigh, 2007), nanomaterials (Batko \& Voelkel, 2007), pharmaceutical excipients and powders (Adamska, Voelkel, \& Heberger, 2007; Cordeiro, Silva, Gomes, \& Rocha, 2010; Swaminathan, Cobb, \& Saracovan, 2006) and also of various synthetic fibers (Heng, Pearse, Thielmann, Lampke, \& Bismarck, 2007; Huang, Li, Shi, \& Li, 2008; Rjiba, Nardin, Drean, \& Frydrych, 2007; Tate, Kamath, Wesson, \& Ruetsch, 1996) and some cellulosic fibers (Abdelmouleh et al., 2004; Belgacem \& Gandini, 1999; Cordeiro, Neto, Gandini, \& Belgacem, 1995; Ren \& BuschleDiller, 2007).

In the present study, IGC was used to characterize surface properties (surface energy and heterogeneity, permeability, monolayer capacity, surface area and acid-base properties) of several vegetable fibers (assai, coir, curaua, jute, piassava, pita Mexicana, ramie, silk floss, sorghum and sisal). Special attention was devoted to the characterization of sisal fibers after alkaline treatment, which is commonly used to promote compatibility between vegetable fibers and hydrophobic materials such as the polymer matrices of composites.

\subsection{Inverse gas chromatography}

Inverse gas chromatography (IGC) is a derivation of conventional gas chromatography but, unlike analytical chromatography, the stationary phase is the sample under study while a known substance in the mobile phase acts as a probe molecule. IGC is a powerful technique which can provide information about various adsorption properties, including surface energy, free energy of adsorption, acid-base characteristics, monolayer capacity, surface area, adsorption isotherm, surface heterogeneity and permeability.

Surface energy is commonly used to describe the energetic situation of a solid surface, being therefore directly related to the adhesion characteristics of a particular material.

The surface energy can be attributed to the dispersive component arising from London, van der Waals and Lifshitz forces (Fowkes, 1964) and the acid-base component arising from Lewis acid-base interactions and hydrogen bonds (Gutmann, 1978). The retention time of a series of homologous n-alkanes is used to determine the dispersive surface energy of the fibers, which is obtained from the expression below (Schultz, Lavielle, \& Martin, 1987):

$\Delta G_{\mathrm{S}}^{\mathrm{D}}=R T \ln V_{\mathrm{N}}=2 N_{\mathrm{A}}\left(\gamma_{\mathrm{S}}^{\mathrm{D}}\right)^{1 / 2} a\left(\gamma_{\mathrm{L}}^{\mathrm{D}}\right)^{1 / 2}+$ const.

where $\Delta G_{\mathrm{s}}^{\mathrm{D}}$ is the dispersive free energy of adsorption, $V_{\mathrm{N}}$ is the net retention volume, $\gamma_{S}^{\mathrm{D}}$ and $\gamma_{\mathrm{L}}^{\mathrm{D}}$ are the dispersive components of the surface tension of the adsorbent (i.e. the fibers) and the adsorbate, respectively, $a$ is the cross sectional area of the adsorbate and $N_{\mathrm{A}}$ is the Avogadro constant.

A comprehensive insight into the Lewis acid-base surface interactions can provide a better understanding of the influence of the chemical-physical surface characteristics of the fibers on their properties and their ability to change through chemical modification (Dorris \& Gray, 1980). When polar probes are used, dispersive and specific interactions take place. Thus, the free energy of adsorption, $\Delta G_{\mathrm{s}}$, is decomposed into two components, dispersive $\left(\Delta G_{\mathrm{s}}^{\mathrm{D}}\right)$ and specific $\left(\Delta G_{\mathrm{s}}^{\mathrm{sp}}\right)$ :

$\Delta G_{\mathrm{s}}=\Delta G_{\mathrm{s}}^{\mathrm{D}}+\Delta G_{\mathrm{s}}^{\mathrm{sp}}$
$\Delta G_{\mathrm{s}}^{\mathrm{sp}}$, corresponding to the polar probes, is a measure of how easily the surface can polarize the probe. $\Delta G_{\mathrm{s}}^{\mathrm{sp}}$ is converted into acidbase constants using the Gutmann concept (Cava, Gavara, Lagarón, \& Voelkel, 2007; Gutmann, 1978; Voelkel, 1991):

$-\frac{\Delta G_{\mathrm{s}}^{\mathrm{sp}}}{\mathrm{AN}^{*}}=\frac{\mathrm{DN}}{\mathrm{AN}^{*}} K_{\mathrm{a}}+K_{\mathrm{b}}$

where $\mathrm{DN}$ is the donor and $\mathrm{AN}^{*}$ is the acceptor values of the polar probes. The constants $K_{\mathrm{a}}$ and $K_{\mathrm{b}}$ describe the acidity and basicity of the fiber surface, respectively.

Using different probes concentrations, the adsorption isotherm can be obtained (Cremer \& Huber, 1962). The retention volume at the peak maximum of each injection is used to determine the monolayer capacity (Eq. (4)) according to BET (Brunauer, Emmet, \& Teller, 1938; Conder \& Young, 1979):

$\frac{n}{n_{\mathrm{m}}}=\frac{C x}{(1-x)[1+(C-1) x]}$

In this equation, $n_{\mathrm{m}}$ is the monolayer capacity, $n$ is the adsorbed amount, $C$ is a constant (related to the heat of adsorption), $x$ is the reduced pressure $\left(p / p^{0}\right)$. A plot of $x /[n(1-x)]$ versus $x$ usually yields a straight line from which $n_{\mathrm{m}}$ can be calculated. If the cross sectional area, $a_{\mathrm{m}}$, of the probe molecule is known the BET surface area, $S_{\mathrm{BET}}$, can be readily calculated using the Avogadro constant, $N_{\mathrm{A}}$ :

$S_{\mathrm{BET}}=n_{\mathrm{m}} a_{\mathrm{m}} N_{\mathrm{A}}$

In addition, from the adsorption isotherm, the partial pressures can be converted into the adsorption potential $(A)$ according to:

$A=R T \ln \left(\frac{p^{0}}{p}\right)$

The first derivative of the adsorbed amount with the adsorption potential $(\mathrm{d} n / \mathrm{d} A)$ gives the distribution of surface sites of distinct energetic levels, i.e. the surface heterogeneity.

The permeability, evaluated through the diffusion coefficient, $D_{\mathrm{P}}$, may also be calculated from IGC using the van Deemter approach (Habgood \& Hanlan, 1959; van Deemter, Zuiderweg, \& Klinkenberg, 1956), shown in Eq. (7):

$C=\left(\frac{16}{\pi}\right)\left(\frac{d^{2}}{D_{\mathrm{p}}}\right)\left[\frac{k}{(1+k)}\right]$

where $d$ is the average diameter and $k$ is the partition coefficient. The constant $C$ is a measure of the equilibrium times and can be related to non-equilibrium effects such as bulk or pore diffusion (Habgood \& Hanlan, 1959).

\section{Materials and methods}

\subsection{Sample preparation}

In this work, Brazilian vegetable fibers, listed in Table 1, were studied. The raw material was collected from mature plants and the fibers obtained following usual processing (retting, decortication, separation, cleaning and outdoor drying).

Sisal fibers were obtained from sisal ropes. In addition, chopped $(40 \mathrm{~mm})$ sisal fibers were chemically treated by immersion in a sodium hydroxide $(\mathrm{NaOH})$ aqueous solution $(5 \%(\mathrm{w} / \mathrm{v})$, fiber:solution ratio of $40 \mathrm{~g}: 1 \mathrm{~L}$ ) for $1 \mathrm{~h}$ at $20^{\circ} \mathrm{C}$, neutralized with an acetic acid aqueous solution $(0.2 \%, w / v)$, repeatedly washed with distilled water and finally dried in an air-circulating oven at $105 \pm 1^{\circ} \mathrm{C}$ for $1 \mathrm{~h}$. All other fibers were used without any prior treatment. 
Table 1

Natural fibers under study: origin and chemical composition.

\begin{tabular}{|c|c|c|c|c|c|}
\hline Fibers source & Species & Origin & Cellulose (\%) & Lignin (\%) & Hemicellulose (\%) \\
\hline Assai & Euterpe oleracea & Fruit & 33 & 33 & 37 \\
\hline Coir & Cocos nucifera & Fruit & $32-53$ & $38-45$ & $0.15-15$ \\
\hline Curaua & Ananas erectifolius & Leaf & $71-74$ & $8-11$ & 21 \\
\hline Jute & Corchorus capsularis & Bast & $59-71$ & $12-16$ & $14-22$ \\
\hline Piassava & Attalea funifera & Leaf & 29 & 45 & 26 \\
\hline Pita Mexicana & Agave lechuguilla & Leaf & 80 & 15 & $3-6$ \\
\hline Ramie & Boehmeria nivea & Bast & $67-76$ & $0.6-0.7$ & $13-16$ \\
\hline Silk floss & Ceiba speciosa & Fruit & 54 & 15 & 28 \\
\hline Sisal & Agave sisalana & Leaf & $60-75$ & $8-12$ & $10-15$ \\
\hline Sorghum & Sorghum bicolor & Leaf & $45-49$ & $19-22$ & $22-28$ \\
\hline
\end{tabular}

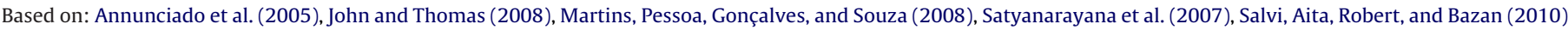
and Vieira, Heinze, Antonio-Cruz, and Mendoza-Martinez (2002)

\subsection{IGC analysis}

IGC measurements were carried out using a commercial inverse gas chromatograph SMS-iGC 2000 (Surface Measurements Systems, London, UK) equipped with flame ionization (FID) and thermal conductivity (TCD) detectors. Standard glass silanized (dymethyldichlorosilane; Repelcote BDH, UK) columns (ID: $4 \mathrm{~mm}$, length: $30 \mathrm{~cm}$ ) were used. Each fiber (around $1.5 \mathrm{~g}$ ) was packed into the columns by vertical tapping ( 20 min at 6 intensity). The columns were then conditioned in the IGC overnight at $60^{\circ} \mathrm{C}$ followed by $2 \mathrm{~h}$ at the specific measurement, condition (for temperature stabilization). After that, pulse injections were carried out using $0.25 \mathrm{~mL}$ gas loop. Methane was the tracer molecule used to calculate the dead time.

Measurements of dispersive interactions were carried out using n-alkanes (hexane, heptane, octane, nonane and decane) at $25^{\circ} \mathrm{C}$ and Helium as the carrier gas (flow rate: $10 \mathrm{~mL} / \mathrm{min}$ ). For the acid-base studies, acetonitrile (ACN), ethyl acetate (EtOAc), dichloromethane (DCM) and tetrahydrofuran (THF) were used. The isotherm experiments were carried out with different concentrations of n-octane at $25^{\circ} \mathrm{C}$ and a flow rate of $10 \mathrm{~mL} / \mathrm{min}$. Permeability studies were done using variable n-octane flow rates at $25^{\circ} \mathrm{C}$. All experiments were carried out at $0 \% \mathrm{RH}$ and at least in duplicate, producing a lower than $3 \%$ variation.

The $i$ GC system used is fully automatic, with SMS $i$ GC Controller v1.8 software. Data were analyzed using iGC Standard v1.3 and Advanced Analysis Software v1.25. The physical constants of the probes used in the IGC calculations were obtained from the literature (Farinato, Kaminski, \& Courter, 1990; Gutmann, 1978; Schultz et al., 1987) and are shown in Table 2.

\subsection{X-ray diffraction}

X-ray diffractograms of the fibers (powdered samples) were recorded in a Siemens X-ray diffractometer model Kristalloflex 810 with a D-500 goniometer, using $40 \mathrm{kV}, 17.5 \mathrm{~mA}$ and $\mathrm{CuK} \alpha$ radiation. A step size of $0.05^{\circ}$ and a step scan of $3 \mathrm{~s}$ were used for the entire reading range $\left(5-55^{\circ}\right)$. Crystallinity was evaluated from the percentage crystallinity index $\left(I_{C}\right)$, using the equation described by Segal, Creely, Martin, and Conrad (1959):

$I_{\mathrm{C}}=\left(1-\frac{I_{\mathrm{am}}}{I_{002}}\right) \times 100 \%$

where $I_{002}$ is the maximum peak intensity at $2 \theta$ angle around $22^{\circ}$, representing the crystalline region, and $I_{\mathrm{am}}$ is the minimum peak intensity at $2 \theta$ angle around $18^{\circ}$, representing the amorphous region.

\subsection{Fourier transform infrared spectroscopy (FTIR)}

FTIR absorption spectrum of the fibers (powdered sample) was obtained in a Perkin Elmer spectrometer model Spectrum 1000, using a $\mathrm{KBr}$ disc containing about $6 \mathrm{wt}$.\% of the fibers. The evaluated wavenumber range varied from 400 to $4000 \mathrm{~cm}^{-1}$, with $4 \mathrm{~cm}^{-1}$ resolution and following 32 scans.

\section{Results and discussion}

Fig. 1 shows the $R T \ln V_{N}$ versus $a\left(\gamma_{L}^{\mathrm{D}}\right)^{1 / 2}$ curves (Eq. (1)) for the n-alkane series obtained for assai, piassava and ramie fibers at $25^{\circ} \mathrm{C}$. In the present study, excellent linear fits (0.9991-0.9996) were obtained for all the analyzed samples.

The calculated values of the dispersive component of the surface energy, $\gamma_{S}^{\mathrm{D}}$, of the fibers are summarized in Table 3 . The results ranged from $38.41 \mathrm{~mJ} / \mathrm{m}^{2}$ for piassava to $52.39 \mathrm{~mJ} / \mathrm{m}^{2}$ for assai, in the following order: piassava $<$ jute $<$ sorghum $<$ ramie $<$ coir $<$ pita Mexicana < curaua < silk floss < sisal < assai. Mills, Gardner, and Wimmer (2008) reported similar dispersive surface energy values for jute, silk floss, coir and sisal $\left(41.9,39.5,39.1\right.$ and $38.4 \mathrm{~mJ} / \mathrm{m}^{2}$, respectively), and Cordeiro, Gouveia, and Jacobi John (2010) reported a dispersive energy of $37.5 \mathrm{~mJ} / \mathrm{m}^{2}$ for sisal fibers from South Africa.

The variation in surface energy can be explained by the particular chemical composition of the fibers, namely the content of

Table 2

Physical constants of the probes used in the IGC experiments.

\begin{tabular}{|c|c|c|c|c|c|}
\hline Probe & $a\left(10^{-19} \mathrm{~m}^{2}\right)$ & $\gamma_{\mathrm{L}}^{\mathrm{D}}\left(\mathrm{mJ} / \mathrm{m}^{2}\right)$ & $\mathrm{DN}(\mathrm{kcal} / \mathrm{mol})$ & $\mathrm{AN}^{*}(\mathrm{kcal} / \mathrm{mol})$ & Specific characteristic \\
\hline n-Hexane & 5.15 & 18.4 & - & - & Neutral \\
\hline n-Heptane & 5.73 & 20.3 & - & - & Neutral \\
\hline$n$-Octane & 6.30 & 21.3 & - & - & Neutral \\
\hline n-Nonane & 6.90 & 22.7 & - & - & Neutral \\
\hline$n$-Decane & 7.50 & 23.4 & - & - & Neutral \\
\hline Acetonitrile & 2.14 & 27.5 & 14.1 & 4.7 & Amphoteric \\
\hline Ethyl acetate & 3.30 & 19.6 & 17.1 & 1.5 & Amphoteric \\
\hline Dichloromethane & 2.45 & 24.5 & - & 3.9 & Acid \\
\hline Tetrahydrofuran & 2.90 & 22.5 & 20.0 & 0.5 & Basic \\
\hline
\end{tabular}

a: Cross-sectional area; $\gamma_{\mathrm{L}}^{\mathrm{D}}$ : surface tension; donor (DN) and acceptor (AN*) values. Based on: Schultz et al. (1987), Farinato et al. (1990), and Gutmann (1978). 


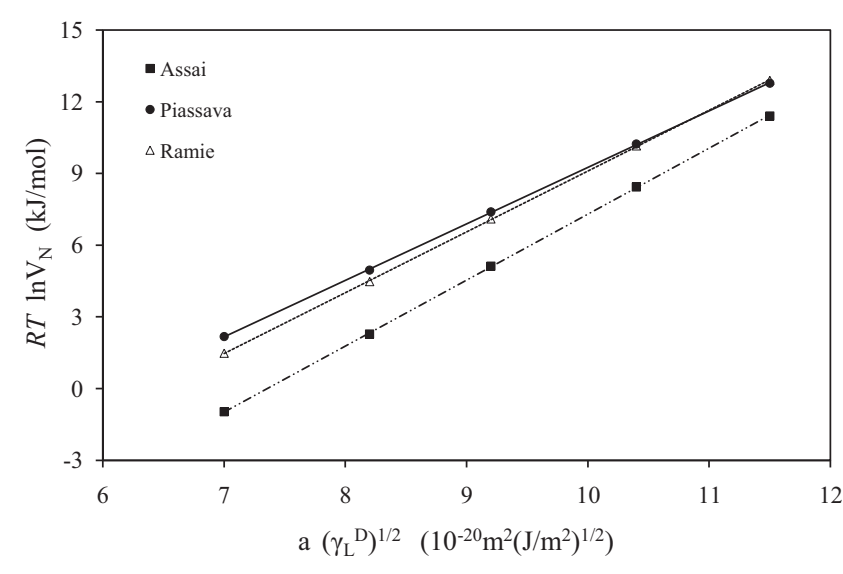

Fig. 1. Plot of $R T \ln V_{\mathrm{N}}$ versus $a\left(\gamma_{\mathrm{L}}^{\mathrm{D}}\right)^{1 / 2}$ obtained with the n-alkanes for assai, piassava and ramie fibers.

the aliphatic components of cellulose, hemicelluloses and lignin. The chemical composition of the fiber surface depends on several factors, two of them being particularly relevant: the plant from which the fibers were extracted and the fiber extraction process itself. Indeed, most of the fibers are covered with a waxy layer that may act as a weak boundary layer in cohesion and adhesion interactions, probably deactivating the surface and, if the extraction process includes a step that removes the wax, a significant change is expected.

The chemical composition may also vary based on the plant growing conditions and the fiber origin. According to the studies carried out by Mills et al. (2008), leaf fibers show higher dispersive surface energy $\left(38.70 \mathrm{~mJ} / \mathrm{m}^{2}\right)$ than bast fibers $\left(37.80 \mathrm{~mJ} / \mathrm{m}^{2}\right)$, the latter being higher than fruit fibers $\left(37.05 \mathrm{~mJ} / \mathrm{m}^{2}\right)$, even though the differences are close to the experimental error. The mean $\gamma_{S}^{\mathrm{D}}$ value obtained in the present work for the different groups was higher for fruit fibers $\left(48.4 \mathrm{~mJ} / \mathrm{m}^{2}\right)$, followed by leaf fibers (average $44.4 \mathrm{~mJ} / \mathrm{m}^{2}$ ) and bast fibers (average $41.7 \mathrm{~mJ} / \mathrm{m}^{2}$ ). But, as found by Mills et al. (2008) at low temperatures, a higher variation in $\gamma_{S}^{\mathrm{D}}$ was observed within the fibers from the same origin than among fibers from different origins. The same authors found a correlation between dispersive surface energy and fiber composition at $40^{\circ} \mathrm{C}$ reporting that surface dispersive energy decreases for higher lignin and hemicellulose content but increases with the cellulose content. Analyzing the fibers of the same origin, in the present study, the highest energy values were observed for the fibers with higher cellulose content, except for assai.

The retention of the probes, and consequently the IGC data, may be influenced by other parameters such as crystallinity and the arrangement and orientation of chemical groups in the surface (Belgacem, Blayo, \& Gandini, 1996; Papirer, Brendle, Balard, \&

Table 3

Dispersive surface energy at $25^{\circ} \mathrm{C}$ and crystallinity index of the studied fibers.

\begin{tabular}{llll}
\hline Fibers & & $\gamma_{\mathrm{S}}^{\mathrm{D}}\left(\mathrm{mJ} / \mathrm{m}^{2}\right)$ & $I_{\mathrm{C}}(\%)$ \\
\hline \multirow{3}{*}{ Fruit } & Assai & 52.39 & 48.5 \\
& Coir & 45.05 & 32.1 \\
& Silk floss & 47.80 & 45.0 \\
Bast & Jute & 38.85 & 51.3 \\
& Ramie & 44.55 & 47.4 \\
& Curaua & 46.72 & 56.7 \\
& Pita Mexicana & 45.50 & 44.1 \\
Leaf & Piassava & 38.41 & 32.4 \\
& Sorghum & 41.43 & 40.9 \\
& Sisal & 48.35 & 49.5 \\
& Sisal (treated) & 45.95 & 43.9 \\
\hline
\end{tabular}

$\gamma_{\mathrm{S}}^{\mathrm{D}}:$ dispersive surface free energy; $I_{\mathrm{C}}$ : crystallinity index.
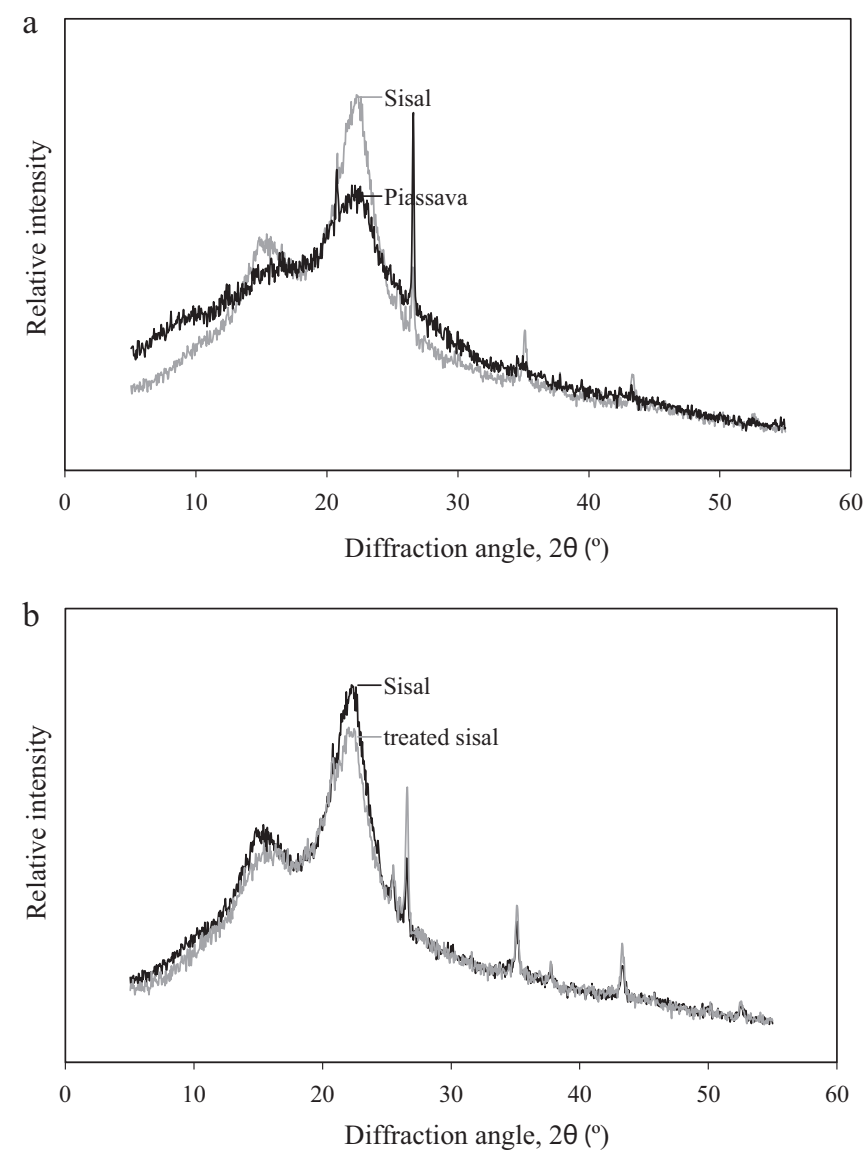

Fig. 2. X-ray diffractogram for piassava and sisal (a), and for sisal before and after $\mathrm{NaOH}$ treatment (b).

Vergelati, 2000). The crystallinity index $\left(I_{C}\right)$ was calculated for the studied fibers (Table 3 ). For the leaf fibers, piassava, with the lowest dispersive surface energy, $I_{C}=32.4 \%$, significantly lower than for sisal $\left(I_{C}=49.5 \%\right)$, which has the highest dispersive surface energy (Fig. 2a). Crystallinity can also explain the high dispersive surface energy measured for assai fiber $\left(I_{C}=48.5 \%\right)$ in comparison with the other fruit fibers $\left(I_{C}=32.1\right.$ and $\left.45.0 \%\right)$.

Regarding the sisal treatment with $\mathrm{NaOH}$, a small decrease in $\gamma_{S}^{\mathrm{D}}$, from 48.35 to $45.95 \mathrm{~mJ} / \mathrm{m}^{2}$, was observed (Table 3). The alkaline treatment is the most used chemical treatment of vegetable fibers and causes disruption of hydrogen bonds and removal of amorphous portions (hemicellulose, lignin and pectins) and impurities, increasing the content of exposed cellulose on the fiber (Li, Tabil, \& Panigrahi, 2007). Observing the FTIR spectra for sisal before and after $\mathrm{NaOH}$ treatment (Fig. 3), the peak around $1740 \mathrm{~cm}^{-1}$, seen in untreated sisal, disappears upon alkali treatment. This is due to the removal of the carboxylic group present in the acids and esters of p-coumaric and uronic acids (main constituents of hemicelluloses) or in aliphatic extractives components remaining as traces in the fibers (Oliveira, Cordeiro, Evtuguin, Torres, \& Silvestre, 2007). The peak around $1380 \mathrm{~cm}^{-1}$ and $1260 \mathrm{~cm}^{-1}$ observed in the untreated sisal fibers indicates the presence of lignin and hemicellulose, respectively. The disappearance of the peak around $1260 \mathrm{~cm}^{-1}$ after alkalization indicates the preferential removal of hemicelluloses materials rather than lignin (Mwaikambo \& Ansell, 2002).

In addition, the alkaline treatment can also lead to an increase in the amount of amorphous cellulose at the expense of crystalline cellulose (Mwaikambo \& Ansell, 2002). Indeed, this treatment causes fiber swelling, and, in this state, the natural crystalline structure of cellulose can relax and turn into cellulose II. The degree of swelling 


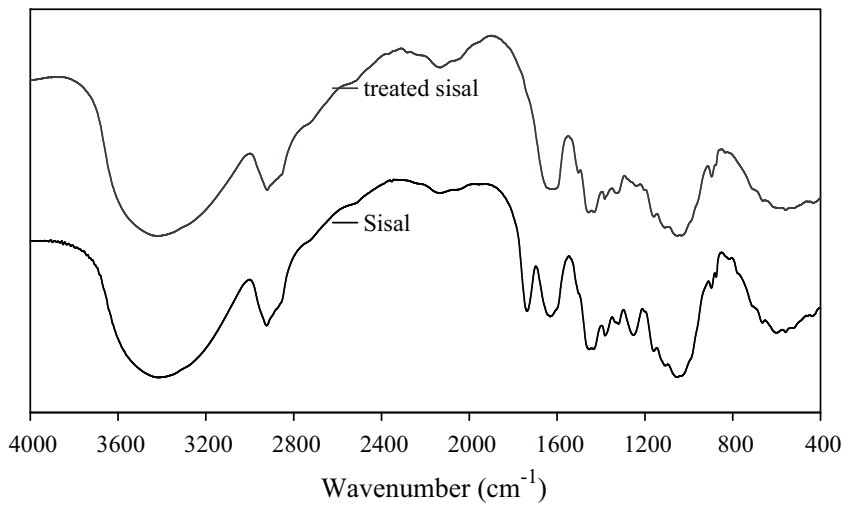

Fig. 3. FTIR spectra of sisal before and after $\mathrm{NaOH}$ treatment.

is influenced by the type and concentration of the alkali, the temperature and the duration of the treatment. Depending on the composition of the lignocellulosic fibers, the alkaline treatment may decrease or increase surface energy. In this work, the X-ray diffractogram of sisal showed a reduction in crystalline cellulose (cellulose I, peak around $22^{\circ}$ ) after $\mathrm{NaOH}$ treatment (Fig. 2b) and the crystallinity index decreased from 49.5 to $43.9 \%$ (Table 3), justifying the reduction in $\gamma_{S}^{\mathrm{D}}$ previously shown.

The specific free energy of adsorption, $\Delta G_{\mathrm{s}}^{\mathrm{sp}}$, was calculated according to Eq. (2), using the difference between the adsorption energy of the polar probe (acetonitrile, ethyl acetate, dichloromethane and tetrahydrofuran) and its dispersive increment ( $\mathrm{n}$-alkane line), as shown in Fig. 4 . The $\Delta G_{\mathrm{s}}^{\mathrm{sp}}$ data given in Table 4 show that piassava established the weaker interaction with all probes. Besides, the higher $\Delta G_{\mathrm{s}}^{\mathrm{sp}}$ for the treated sisal clearly indicates that the alkaline treatment creates new active sites for specific interactions.

The calculated $\Delta G_{\mathrm{s}}^{\mathrm{sp}}$ values were converted into acid-base constants using the Gutmann concept (Eq. (3)). The coefficients of determination obtained for the linear fitting of the data (Fig. 5) were in the 0.993-0.9996 range, showing that the Gutmann's acid-base concept is valid for the studied systems and that the specific interactions may be considered of the electron donor-acceptor type. The obtained constants, describing surface acidity $\left(K_{\mathrm{a}}\right)$ and basicity $\left(K_{\mathrm{b}}\right)$ of the fibers, are shown in Table 4. All fibers exhibited a Lewis basic character with curaua and sisal showing the lowest $K_{\mathrm{b}} / K_{\mathrm{a}}$ ratio (1.27 and 1.33 , respectively), and pita Mexicana and assai the highest (4.00 and 3.10, respectively) (Fig. 5a). In addition, the sisal alkaline treatment induced a significant increment (Fig. 5b) of the basic character of the fiber (from 1.33 to 2.27). Mills et al. (2008) also

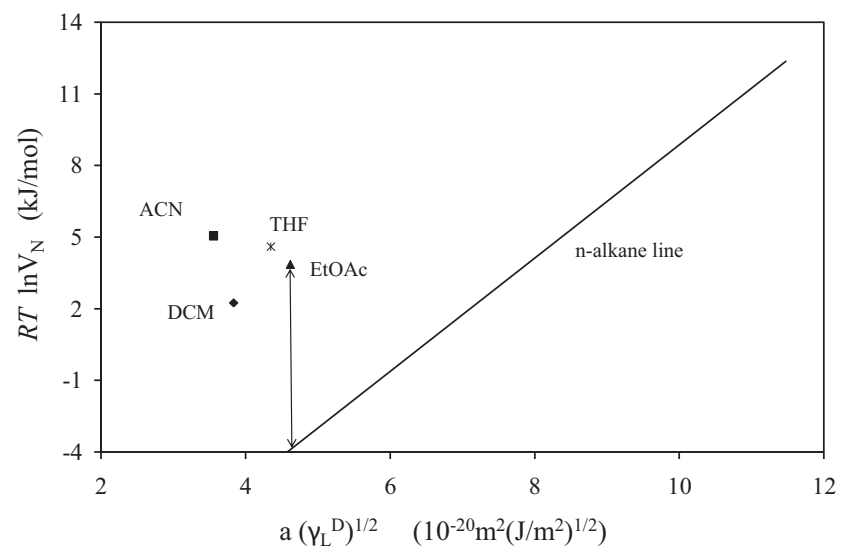

Fig. 4. Plot of $R T \ln V_{\mathrm{N}}$ versus $a\left(\gamma_{\mathrm{L}}^{\mathrm{D}}\right)^{1 / 2}$ obtained using n-alkanes and polar probes for jute fibers.
Table 4

Specific free energy of adsorption and acid/base constants obtained for the fibers at $25^{\circ} \mathrm{C}$.

\begin{tabular}{lrrrrrrr}
\hline \multirow{2}{*}{ Fibers } & \multicolumn{2}{c}{$\Delta G_{\mathrm{s}}^{\mathrm{sp}}(\mathrm{kJ} / \mathrm{mol})$} & & \multicolumn{2}{l}{$K_{\mathrm{a}}$} & $K_{\mathrm{b}}$ & $K_{\mathrm{b}} / K_{\mathrm{a}}$ \\
\cline { 2 - 5 } & \multicolumn{1}{c}{$\mathrm{ACN}$} & EtOAc & \multicolumn{1}{c}{ DMC } & THF & & & \\
\hline Assai & 13.19 & 8.79 & 8.50 & 9.17 & 0.10 & 0.31 & 3.10 \\
Coir & 10.19 & 8.11 & 7.74 & 8.83 & 0.10 & 0.19 & 1.90 \\
Silk floss & 13.10 & 8.69 & 10.05 & 9.54 & 0.11 & 0.27 & 2.45 \\
Jute & 11.48 & 7.76 & 8.01 & 9.14 & 0.10 & 0.17 & 1.70 \\
Ramie & 11.64 & 7.58 & 8.09 & 9.04 & 0.10 & 0.18 & 1.80 \\
Curaua & 10.03 & 8.53 & 9.52 & 9.65 & 0.11 & 0.14 & 1.27 \\
Pita Mexicana & 14.85 & 7.86 & 7.56 & 8.50 & 0.09 & 0.36 & 4.00 \\
Piassava & 9.30 & 7.10 & 7.13 & 7.98 & 0.09 & 0.15 & 1.67 \\
Sorghum & 9.69 & 7.45 & 7.69 & 8.42 & 0.10 & 0.15 & 1.50 \\
Sisal & 10.05 & 6.16 & 7.42 & 7.76 & 0.09 & 0.12 & 1.33 \\
Sisal (treated) & 13.95 & 8.50 & 8.63 & 9.89 & 0.11 & 0.25 & 2.27 \\
\hline
\end{tabular}

$\Delta G_{\mathrm{s}}^{\mathrm{sp}}$ : specific free energy of adsorption; ACN: acetonitrile; EtOAc: ethyl acetate; DMC: dichloromethane; THF: tetrahydrofuran; acid $\left(K_{\mathrm{a}}\right)$ and base $\left(K_{\mathrm{b}}\right)$ constants.

reported the basic character of the surface of vegetable fibers ( 7.5 for silk floss, 1.05 for coir and 1.94 for sisal) and concluded that the acid-base surface properties depend on fiber type and, most of all, the extraction process.

Fig. 6 shows a representative example of the shape of the peaks obtained from the n-octane FID response at different concentrations, which were used to calculate the isotherm curve. This kind of peak is typical of linear adsorption isotherms described by Henry's Law (Fig. 7). The BET specific surface area, $S_{\mathrm{BET}}$, was calculated according Eq. (5) and is shown in Table 5. This parameter was found to vary within $0.096-2.793 \mathrm{~m}^{2} / \mathrm{g}$, corresponding to pita Mexicana and piassava, respectively. Jute, treated sisal and ramie also displayed high surface area, above $2 \mathrm{~m}^{2} / \mathrm{g}$.
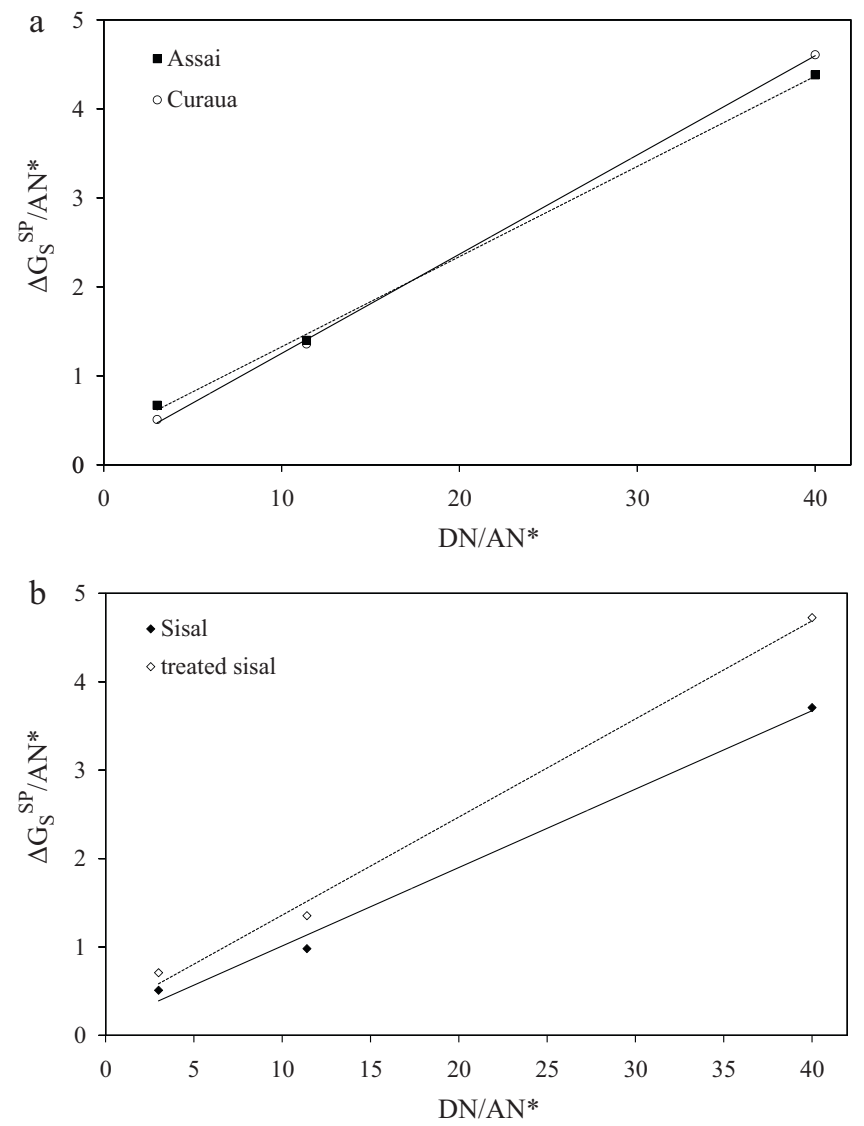

Fig. 5. Plot of $\Delta G_{\mathrm{s}}^{\mathrm{sp}} / \mathrm{AN} *$ versus $\mathrm{DN} / \mathrm{AN}^{*}$ for curaua and assai (a), and for sisal before and after $\mathrm{NaOH}$ treatment (b). 


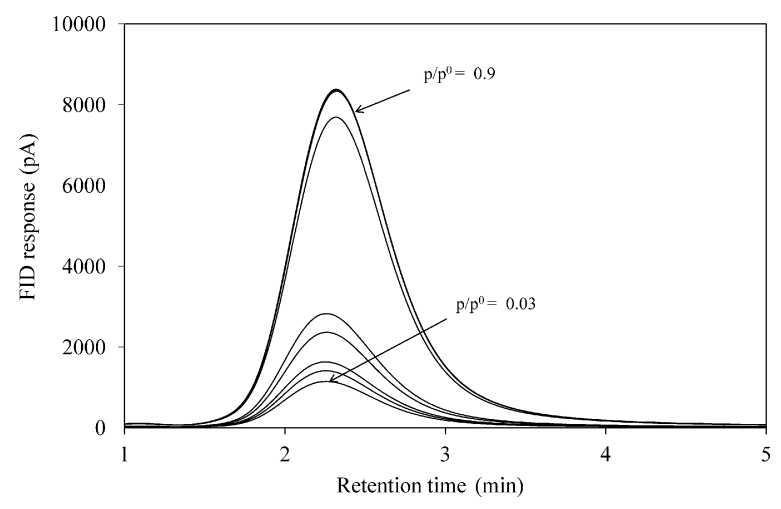

Fig. 6. IGC n-octane peaks at different concentrations obtained for jute fibers.

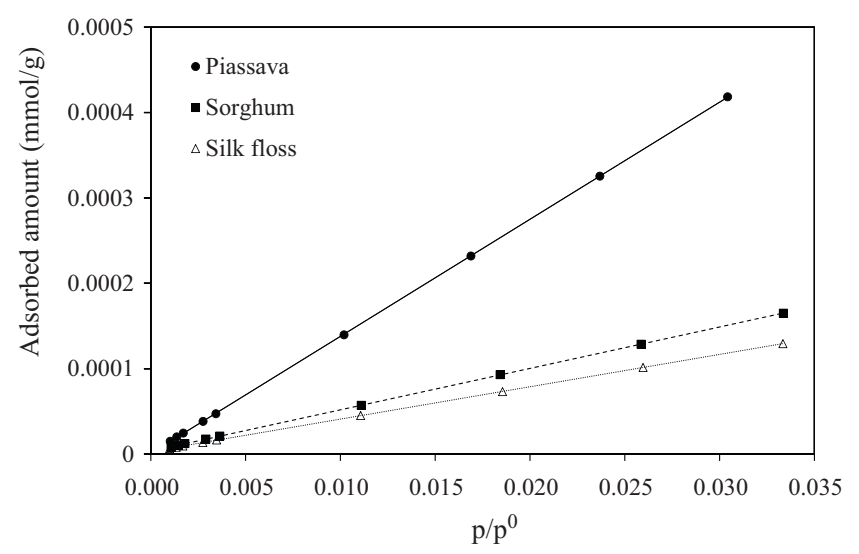

Fig. 7. n-octane isotherms obtained for piassava, sorghum and silk floss fibers.

For some fibers, high surface area was associated with high surface energy. However, this is not always true because larger surface area means larger number of units whereas higher surface energy means higher concentration of active sites or even a change in composition per unit surface. A parameter that can be undoubtedly related to surface area is monolayer capacity, $n_{\mathrm{m}}$ (Eq. (4)), in a way that the larger the surface area, the higher the monolayer capacity. The n-octane monolayer capacity of the fibers was found to vary between 0.0003 (for pita Mexicana), and $0.0074 \mathrm{mmol} / \mathrm{g}$ (for piassava), as shown in Table 5.

The defibrillation process brought about by the alkaline treatment of sisal led to an increase in surface area (from 1.633 to $2.392 \mathrm{~m}^{2} / \mathrm{g}$ ) and consequently increased the monolayer capacity (from 0.0043 to $0.0063 \mathrm{mmol} / \mathrm{g}$ ). This can also explain the decrease in the diffusion coefficient (Eq. (7)) from $8.17 \times 10^{-4}$ to $4.25 \times 10^{-4} \mathrm{~cm}^{2} / \mathrm{s}$ (Table 5).

Table 5

Specific surface area, monolayer capacity, diffusion coefficient and adsorption potential distribution maximum of the fibers at $25^{\circ} \mathrm{C}$.

\begin{tabular}{lllll}
\hline Fibers & $S_{\text {BET }}\left(\mathrm{m}^{2} / \mathrm{g}\right)$ & $n_{\mathrm{m}}(\mathrm{mmol} / \mathrm{g})$ & $D_{\mathrm{p}}\left(10^{-4} \mathrm{~cm}^{2} / \mathrm{s}\right)$ & $A_{\max }(\mathrm{kJ} / \mathrm{mol})$ \\
\hline Assai & 0.382 & 0.0010 & 8.92 & 9.17 \\
Coir & 0.481 & 0.0013 & 6.19 & 8.40 \\
Silk floss & 0.975 & 0.0026 & 3.97 & 8.73 \\
Jute & 2.006 & 0.0053 & 6.67 & 9.46 \\
Ramie & 2.580 & 0.0068 & 5.92 & 11.37 \\
Curaua & 0.868 & 0.0023 & 5.87 & 10.49 \\
Pita Mexicana & 0.096 & 0.0003 & 7.46 & 6.94 and 12.6 \\
Piassava & 2.793 & 0.0074 & 19.8 & 8.96 \\
Sorghum & 0.498 & 0.0013 & 10.4 & 8.73 \\
Sisal & 1.633 & 0.0043 & 8.17 & 13.01 \\
Sisal (treated) & 2.392 & 0.0063 & 4.25 & 10.30 \\
\hline
\end{tabular}

$S_{\mathrm{BET}}$ : BET specific surface area; $n_{\mathrm{m}}$ : monolayer capacity; $D_{\mathrm{p}}$ : diffusion coefficient; $A_{\text {max }}$ : adsorption potential distribution maximum.
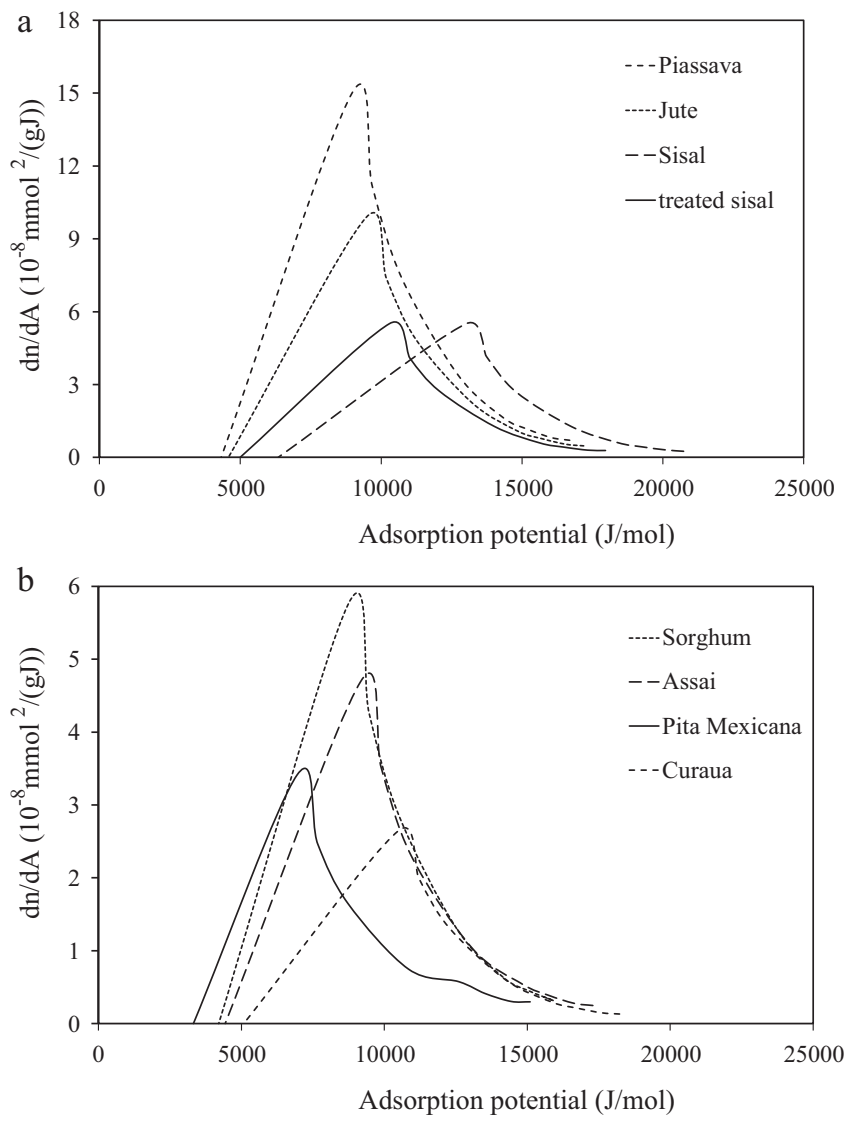

Fig. 8. Heterogeneity profiles obtained with n-octane for piassava, jute and sisal (before and after $\mathrm{NaOH}$ treatment) (a), and for sorghum, assai, pita Mexicana and curaua (b).

The diffusion coefficient with n-octane for the different fibers varied between $3.97 \times 10^{-4}$, (for silk floss) and $1.98 \times 10^{-3} \mathrm{~cm}^{2} / \mathrm{s}$ (for piassava) (Table 5). The $D_{\mathrm{p}}$ parameter is related to sample size and, consequently, to its tendency to agglomerate, although nature and surface heterogeneity of the sample also affect $D_{\mathrm{p}}$.

A parameter not sufficiently studied in vegetal fibers, despite its importance in many applications, is surface heterogeneity. There are two types of surface heterogeneity: structural and energetic. The former refers to the distribution of pore size and shape, being mainly a geometrical effect determined by the correlation between probe molecule size and pore diameter, whereas the latter refers to the distribution of surface sites of distinct energetic levels including surface groups, impurities and/or surface irregularities.

Fig. 8 shows a comparison of the heterogeneity profiles of the studied fibers. All heterogeneity curves showed a single maximum, except for pita Mexicana that showed two peaks, in the evaluated range of adsorption potential. The highest $A_{\max }$ obtained from the heterogeneity profile of each fiber is presented in Table 5. Sisal showed a peak maximum located at higher energy sites, $13.01 \mathrm{~kJ} / \mathrm{mol}$ (Fig. 8a), followed by ramie with a maximum at $11.37 \mathrm{~kJ} / \mathrm{mol}$. For pita Mexicana, the peak was found at lower adsorption potential $(6.94 \mathrm{~kJ} / \mathrm{mol})$ and some octane molecules seem to occupy even higher energy sites, resulting in a second peak at $12.6 \mathrm{~kJ} / \mathrm{mol}$ (Fig. $8 \mathrm{~b}$ ). In addition, the pita Mexicana presented a less strong curve. The area under the curve, that is related to the uptake of the different energy sites, suggests a larger number of low energy sites of pita Mexicana in comparison with high energy sites. Comparing the heterogeneity profiles, piassava presented the most intense curve in contrast to pita Mexicana. 
Finally, the $\mathrm{NaOH}$ treatment of sisal shifted the peak maximum to lower adsorption potential (from 13.01 to $10.30 \mathrm{~kJ} / \mathrm{mol}$ ) but did not cause a significant change in its adsorption capacity.

\section{Conclusions}

IGC was exhaustively applied to determine the surface properties, namely, dispersive surface energy, acid-base properties, adsorption isotherms, surface area, permeability and surface heterogeneity of ten different fibers. The dispersive component of surface energy varied with fiber type, being related to fiber composition and crystallinity. The fruit fibers showed the highest values followed by the leaf fibers and bast fibers, being the variation in $\gamma_{S}^{\mathrm{D}}$ higher within the fibers of the same origin than among fibers from different origins. In general, for a particular fiber origin, the fibers with higher cellulose content showed the highest energy values.

All fibers presented a Lewis basic character, with $K_{\mathrm{a}}$ from 0.09 to 0.11 and $K_{\mathrm{b}}$ from 0.12 to 0.36 . The surface area of the fibers varied significantly, from 0.096 to $2.793 \mathrm{~m}^{2} / \mathrm{g}$ for pita Mexicana and piassava, respectively. Fibers with large surface area did not necessarily display high surface energy. In the surface heterogeneity evaluations, pita Mexicana appeared to be the most heterogeneous one, showing an additional octane peak.

The simple alkaline treatment of sisal with $\mathrm{NaOH}$ was responsible for yielding a variety of modifications on its physical-chemical characteristics. The treatment reduced the dispersive surface energy due to the interaction with lower energetic sites in the fiber surface. It also promoted interaction with all polar probes used, with a noteworthy increment of the basic character of the fiber. Moreover, the treatment significantly increased the surface area (from 1.633 to $2.392 \mathrm{~m}^{2} / \mathrm{g}$ ) and decreased the diffusion coefficient.

The obtained results suggest that some of the fibers showed higher potential to be used as reinforcement for composites with specific coupling agents and under certain processing conditions. However, it is important to bear in mind that the mechanical performance of a particular composite is dependent not only on fiber surface properties but also on a few other factors, such as length, distribution and mechanical properties of the fibers along with the specific manufacturing conditions used to a particular fiber.

\section{Acknowledgements}

Portuguese authors would like to thank the "Programa Nacional de Re-equipamento Científico", POCI 2010, for sponsoring IGC work (FEDER and Foundation for the Science and Technology). Brazilian authors are thankful to CNPq and CAPES.

\section{References}

Abdelmouleh, M., Boufi, S., Belgacem, M. N., Duarte, A. P., Ben Salah, A., \& Gandini, A. (2004). Modification of cellulosic fibres with functionalised silanes: Development of surface properties. International Journal of Adhesion and Adhesives, 24, 43-54.

Adamska, K., Voelkel, A., \& Heberger, K. (2007). Selection of solubility parameters for characterization of pharmaceutical excipients. Journal of Chromatography A, 1171, 90-97.

Amico, S. C., Angrizani, C. C., \& Drummond, M. L. (2010). Influence of the stacking sequence on the mechanical properties of glass/sisal hybrid composites. Journal of Reinforced Plastics and Composites, 29, 179-189.

Annunciado, T., Amico, S., \& Sydenstricker, T. (2005). Utilização da fibra de paina (chorisia speciosa) como sorvente de óleo cru. Parte II: Caracterização da fibra x capacidade de sorção. Anais do $3^{\circ}$ Congresso Brasileiro de PE'D em Petróleo e Gás. Brazil.

Batko, K., \& Voelkel, A. (2007). Inverse gas chromatography as a tool for investigation of nanomaterials. Journal of Colloid and Interface Science, 315, 768-771.

Belgacem, M. N., Blayo, A., \& Gandini, A. (1996). Surface characterization of polysaccharides, lignins, printing ink pigments, and ink fillers by inverse gas chromatography. Journal of Colloid and Interface Science, 182, 431-436.

Belgacem, M. N., \& Gandini, A. (1999). IGC as a tool to characterize dispersive and acid-base properties the surface of fibers and powders. In E. Pfefferkorn
(Ed.), Interfacial Phenomena in Chromatography (pp. 41-124). New York: Marcel Dekker Inc (Chapter 2)

Brunauer, S., Emmet, P. H., \& Teller, E. (1938). Adsorption of gases in multimolecular layers. Journal of the American Chemical Society, 60, 309-319.

Cava, D., Gavara, R., Lagarón, J. M., \& Voelkel, A. (2007). Surface characterization of poly(lactic acid) and polycaprolactone by inverse gas chromatography. Journal of Chromatography A, 1148, 86-91.

Conder, J., \& Young, C. (1979). Physicochemical measurement by gas chromatography. Chichester, UK: John Wiley \& Sons.

Cordeiro, N., Aurenty, P., Belgacem, M. N., Gandini, A., \& Neto, C. P. (1997). Surface properties of suberin. Journal of Colloid and Interface Science, 187, 498-508.

Cordeiro, N., Gouveia, C., \& Jacobi John, M. (2010). Investigation of surface properties of physico-chemically modified natural fibres using inverse gas chromatography. Industrial Crops and Products, in press, doi:10.1016/j.indcrop.2010.09.008.

Cordeiro, N., Neto, C. P., Gandini, A., \& Belgacem, M. N. (1995). Characterization of the cork surface by inverse gas chromatography. Journal of Colloid and Interface Science, 174, 246-249.

Cordeiro, N., Silva, J., Gomes, C., \& Rocha, F. (2010). Bentonite from Porto Santo Island Madeira archipelago: Surface properties studied by inverse gas chromatography. Clay Minerals, 45, 77-86.

Cremer, E., \& Huber, H. (1962). Measurement of adsorption isotherms by means of high temperature elution gas chromatography. International Symposium on Capillary Chromatography, 3, 169-182.

Dorris, G. M., \& Gray, D. G. (1980). Adsorption of normal-alkanes at zero surface coverage on cellulose paper and wood fibers. Journal of Colloid and Interface Science, 77, 353-362.

Farinato, R. S., Kaminski, S. S., \& Courter, J. L. (1990). Acid-base character of carbonfiber surfaces. Journal of Adhesion Science and Technology, 4, 633-652.

Fowkes, F. M. (1964). Attractive forces at interfaces. Industrial and Engineering Chem istry, 56, 40-52.

Gutmann, V. (1978). The donor-acceptor approach to molecular interactions. New York: Plenum Press.

Habgood, H. W., \& Hanlan, J. F. (1959). A gas chromatographic study of the adsorptive properties of a series of activated charcoals. Canadian Journal of Chemistry-Revue Canadienne de Chimie, 37, 843-855.

Heng, J. Y. Y., Pearse, D. F., Thielmann, F., Lampke, T., \& Bismarck, A. (2007). Methods to determine surface energies of natural fibres: A review. Composite Interfaces, $14,581-604$.

Huang, X. H., Li, B., Shi, B. L., \& Li, L. P. (2008). Investigation on interfacial interaction of flame retarded and glass fiber reinforced PA66 composites by IGC/DSC/SEM. Polymer, 49, 1049-1055.

John, M. J., \& Thomas, S. (2008). Biofibres and biocomposites. Carbohydrate Polymers, $71,343-364$

Kalia, S., Kaith, B. S., \& Kaur, I. (2009). Pretreatments of natural fibers and their application as reinforcing material in polymer composites-A review. Polymer Engineering and Science, 49, 1253-1272.

Li, X., Tabil, L. G., \& Panigrahi, S. (2007). Chemical treatments of natural fiber for use in natural fiber-reinforced composites: A review. Journal of Polymers and the Environment, 15, 25-33.

Martins, M. A., Pessoa, J. D. C., Gonçalves, P. S., \& Souza, F. I. (2008). Thermal and mechanical properties of the açaí fiber/natural rubber composites. Journal of Materials Science, 43, 6531-6538.

Mills, R. H., Gardner, D. J., \& Wimmer, R. (2008). Inverse gas chromatography for determining the dispersive surface free energy and acid-base interactions of sheet molding compound-Part II 14 ligno-cellulosic fiber types for possible composite reinforcement. Journal of Applied Polymer Science, 110, 3880-3888.

Mwaikambo, L. Y., \& Ansell, M. P. (2002). Chemical modification of hemp, sisal, jute, and kapok fibers by alkalization. Journal of Applied Polymer Science, 84 2222-2234.

Oliveira, L., Cordeiro, N., Evtuguin, D. V., Torres, I. C., \& Silvestre, A. J. D. (2007) Chemical composition of different morphological parts from "dwarf cavendish" banana plant and their potential as a non-wood renewable source of natural products. Industrial Crops and Products, 26, 163-172.

Papirer, E., Brendle, E., Balard, H., \& Vergelati, C. (2000). Inverse gas chromatography investigation of the surface properties of cellulose. Journal of Adhesion Science and Technology, 14, 321-337.

Ren, X. H., \& Buschle-Diller, G. (2007). Oxidoreductases for modification of linen fibers. Colloids and Surfaces A-Physicochemical and Engineering Aspects, 299, $15-21$.

Rjiba, N., Nardin, M., Drean, J. Y., \& Frydrych, R. (2007). A study of the surface properties of cotton fibers by inverse gas chromatography. Journal of Colloid and Interface Science, 314, 373-380.

Salvi, D. A., Aita, G. M., Robert, D., \& Bazan, V. (2010). Dilute ammonia pretreatment of sorghum and its effectiveness on enzyme hydrolysis and ethanol fermentation. Applied Biochemistry and Biotechnology, 161, 67-74.

Satyanarayana, K. G., Guimarães, J. L., \& Wypych, F. (2007). Studies on lignocellulosic fibers of Brazil. Part I: Source, production, morphology, properties and applications. Composites Part A: Applied Science and Manufacturing 38, 1694-1709.

Satyanarayana, K. G., Wypych, F., Guimarães, J. L., Amico, S. C., Sydenstricker, T. H. D. \& Ramos, L. P. (2005). Studies on natural fibers of Brazil and green composites. Metals Materials and Processes, 17, 183-194.

Schultz, J., Lavielle, L., \& Martin, C. (1987). The role of the interface in carbon-fiber epoxy composites. Journal of Adhesion, 23, 45-60.

Segal, L., Creely, J. J., Martin, A. E., \& Conrad, C. M. (1959). An empirical method for estimating the degree of crystallinity of native cellulose using the X-ray diffractometer. Textile Research Journal, 29, 786-794. 
Spinacé, M. A. S., Lambert, C. S., Fermoselli, K. K. G., \& De Paoli, M. A. (2009). Characterization of lignocellulosic curaua fibres. Carbohydrate Polymers, 77, 47-53.

Swaminathan, V., Cobb, J., \& Saracovan, I. (2006). Measurement of the surface energy of lubricated pharmaceutical powders by inverse gas chromatography. International Journal of Pharmaceutics, 312, 158-165.

Tate, M. L., Kamath, Y. K., Wesson, S. P., \& Ruetsch, S. B. (1996). Surface energetics of nylon 66 fibers. Journal of Colloid and Interface Science, 177, 579-588.

van Deemter, J. J., Zuiderweg, F. J., \& Klinkenberg, A. (1956). Longitudinal diffusion and resistance to mass transfer as causes of nonideality in chromatography. Chemical Engineering Science, 5, 271-289.
Vieira, M. C., Heinze, T., Antonio-Cruz, R., \& Mendoza-Martinez, A. M. (2002). Cellulose derivatives from cellulosic material isolated from Agave lechuguilla and fourcroydes. Cellulose, 9, 203-212.

Voelkel, A. (1991). Inverse gas chromatography: Characterization of polymers, fibers, modified silicas and surfactants. Critical Reviews in Analytical Chemistry, 22, 411-439.

Wu, R. Q., Que, D., \& Al-Saigh, Z. Y. (2007). Surface and thermodynamic characterization of conducting polymers by inverse gas chromatography: II. Polyaniline and its blend. Journal of Chromatography A, 1146, 93-102. 